\title{
Comparison of Vertical Ground Reaction Forces during Jump between Elderly and Young Adults using Nintendo Wii Balance Board
}

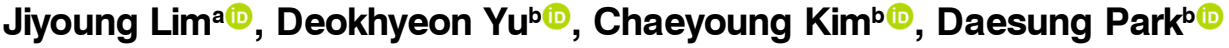 \\ aDepartment of Physical Therapy, Graduate School of Medical Sciences, Konyang University, Daejeon, Republic of Korea \\ ${ }^{b}$ Department of Physical Therapy, College of Medical Science, Konyang University, Daejeon, Republic of Korea
}

Objective: The purpose of this study was to quantitatively evaluate the Wii Balance Board (WBB)-based jump performance for the elderly and to confirm the difference in jump performance according to age.

Design: Cross-sectional study.

Methods: 40 young adults (aged 22.5 \pm 2.2 years) and 33 elderly (aged $75.1 \pm 5.2$ years) without orthopedics disease participated in this study. Standing on the WBB then, with the signal "start," jump vertically to the maximum height at which you can jump, land on the force plate after jump and keep it standing on both feet. All subjects were required to practice the jump sufficiently before starting the measurement, each measuring three times, and the mean values were used. A one-minute break was provided between each trial. Evaluators waited within 1meter for every test to prepare for fall.

Results: The vertical ground reaction force of elderly and young adults when jumping using WBB showed a significant difference $(\mathrm{p}<0.05)$ and demonstrated discriminant validity. Between two groups, there were significant differences in overall jump time $(p$ $<0.05)$, maximum value $(\mathrm{p}<0.05)$, minimum value $(\mathrm{p}<0.05)$, center of pressure $(C O P)$ pathlength $(\mathrm{p}<0.05)$, and flight time $\mathrm{p}$ $<0.05)$.

Conclusions: This study found that performing the vertical jump, the elderly showed longer jump time, lower vertical ground reaction force, COP pathlength and shorter flight phase than healthy young adults using WBB and demonstrated that as a measurement tool, WBB discriminated vertical jump performance between elderly and young adults.

Key Words: Geriatric assessment, Biomedical technology, Physical functional performance

서론

노인은 나이가 증가함에 따라, 근력 약화 및 신경근 기 능장애가 발생하고 일상 활동 가동성이 저하되고, 균형조 절능력이 손상된다. 그로 인해서 기능적인 움직임을 수행 하는 능력이 낮아진다 $[1,2]$. 특히 수직 점프는 단일노화 에 따른 골격근량 감소와 연관되어[3] 노인의 하지근력을 확인할 수 있는 대표적인 움직임이다[4]. 또한, 수직 점프 는 발목 관절, 무릎 관절, 엉덩 관절과 같은 다관절 움직 임이 요구되는 동작으로, 노인의 기능적인 움직임 능력과
일상생활 과제 수행 능력을 보다 민감하게 평가할 수 있 다[5-7].

점프 시 발생하는 수직지면반발력은 움직임 동안 발로 딛고 있는 지면에 대해 수직으로 작용하는 반발력으로, 움직임 능력과 근력을 평가하는 데 유용한 변수가 된다 [8]. 기존 연구에 따르면, 노인과 성인을 대상으로 다리 를 구부린 자세에서 수직 점프를 하는 동안 구심성, 원심 성 수축 시에 노인에서 대퇴이두근과 대퇴직근의 근육활 성과 지면반발력이 줄어들었음을 근전도검사와 힘판으로 확인하였다[9]. 신체를 감속시키는 착지동작은 바닥과 지

Received: Apr 6, 2021 Revised: May 25, 2021 Accepted: May 30, 2021

Corresponding author: Daesung Park (ORCID https://orcid.org/0000-0003-4258-0878)

Department of Physical Therapy, College of Medical Sciences, Konyang University

158 Gwanjeodong-ro, Seo-gu, Daejeon, Republic of Korea [35365]

Tel: + 82-10-3771-9771 Fax: + 82-42-600-6565 E-mail: daeric@konyang.ac.kr

This is an Open-Access article distributed under the terms of the Creative Commons Attribution Non-Commercial License (http://creativecommons.org/licenses/ by-nc/4.0) which permits unrestricted non-commercial use, distribution, and reproduction in any medium, provided the original work is properly cited.

Copyright @ 2021 Korean Academy of Physical Therapy Rehabilitation Science 
면의 충돌 시에 몸에 충격력을 발생시키고, 착지 시 발생 하는 충격력은 신체에 전달되어 상해를 발생시키는 요인 으로 작용한다. 무릎과 엉덩관절의 굽힘각도가 클수록 상해의 위험이 더 적어지고 수직지면반발력이 커진다 [10].

노인과 성인의 점프 수행력 평가 시, 수직지면반발력 또는 압력중심점 이동거리를 측정하기 위해 실험실기반 의 힘판이 널리 사용되어 왔다[11-13]. 반면 $\mathrm{Wii}$ Balance Board(WBB)는 힘판보다 임상에서 사용이 쉽 고 간단하며 이동성이 좋은 장비이며, 다양한 질환을 대 상으로 보행 및 균형 능력 평가에 대한 신뢰도 및 타당 도가 입증되어왔다 $[11,14,15]$. 특히, 실험실 기반 힘판 을 이용한 균형 능력 평가와 임상 기반의 균형 능력 평 가의 중간 역할로서, 그 활용 가능성이 제고된 바 있다 [16].

건강한 성인 10 명을 대상으로, $\mathrm{WBB}$ 의 점프 훈련 기 기로서 타당성을 확인한 연구[17]에 따르면, 수직 점프 동 안 측정된 수직지면반발력이 힘판으로 측정된 결과와 매 우 높은 일치도를 보였다. 이를 통해 $\mathrm{WBB}$ 의 점프 수행 력 평가 시 측정된 수직지면반발력에 대한 높은 타당성을 확보하였으나, 지금까지 노인을 대상으로 $\mathrm{WBB}$ 를 활용하 여 수직 점프 수행력을 평가한 연구가 없었다. 또한, 수직 점프 능력 검사는 운동 선수부터 건강한 성인, 허약한 환 자까지 다양하게 활용 가능하고[18], 수직 점프 능력을 통 해 신경근 기능 저하와 함께 근육간 공동 작용 패턴을 알 수 있었기 때문에 $[9,19]$ 건강한 성인과 노인의 수직 점프 능력을 $\mathrm{WBB}$ 로 측정하고 이를 비교한 기초 연구가 필요 하다. 따라서, 본 연구의 목적은 노인을 대상으로 WBB기 반 점프 수행력을 정량적으로 확인함으로써 $\mathrm{WBB}$ 활용성 을 확보하고, 연령에 따른 점프 수행력의 차이를 확인하 는 데 있다.

\section{연구 방법}

\section{연구 설계 및 연구 대상자}

본 연구의 설계는 단면조사연구로, 대전시 서구에 위치 한 경로당에서 65 세 이상 노인과 대전시 서구 소재의 대 학교에서 만 19 세 이상의 건강한 젊은 성인을 각각 모집 하였다.

대상자 선정기준은 다음과 같다. 첫째, 신경계 또는 하 지 근골격계 질환이 없는 자, 둘째, 독립적으로 보조도구 없이 앉았다 일어서기, 보행, 점프가 가능한 자, 셋째, 최 근 1 년 이내 낙상경험이 없는 자, 넷째, 최근 1 년 이내 골 반과 다리에 골절경험이 없는 자이다. 제외기준은 다음과 같다. 첫째, 하지 정형외과적 질환(류마티스 관절염, 연골
또는 인대 손상 등)이 있는 자, 둘째, 연구 과정에 있는 지시 사항을 이해하지 못하고 의사소통이 불가능한 자, 셋째, 임산부, 넷째, 빈혈로 약물을 복용한 적이 있는 자 이다.

모든 대상자에게 연구의 목적과 방법에 대해 실험 전 본 연구에 대한 충분한 설명을 제공하였고, 모든 대상자 는 동의서에 서명하고 자발적으로 참여하였다. 본 연구는 건양대학교 임상시험심사위원회(Institutional Review Board) 의 승인 하에 실시하였다(IRB 승인번호: 2018-121-01).

\section{측정 도구 및 방법}

젊은 성인과 노인의 점프 수행력을 비교하기 위해, WBB(WBB, Nintendo of America Inc., USA)와 Balancia software(ver. 2.0, Mintosys Inc., Korea)[20]를 사용하였고, 데이터 샘플링은 $100 \mathrm{~Hz}$ 로 설정하였다. $\mathrm{WBB}$ 를 사용하여 점프시의 동작을 수직지면반발력(체 중\%)의 최댓값, 최솟값, 체공시간을 시작점으로부터 종말 지점을 그래프로 나타낸 것이다(Figure 1). A-D구간은 초 기구간(Mean-3SD)값보다 낮아지기 시작하는 시점부터 말기구간(Mean+3SD)값보다 커지기 시작한 시점으로, 전 체 점프 시간을 나타낸다. 그 중 $\mathrm{B}$ 구간은 공중에서 머문 시간(체공시간)을 의미한다. $\mathrm{C}$ 시점은 전체영역에서 최댓 값 즉, 발에 압력이 최대로 증가한 상태로 최대하중이 실 렸을 때를 의미한다.

\section{연구 절차}

대상자는 WBB 위에 두 발로 올라선 후 엄지 발가락 을 위치를 맞추고 양팔은 편안하게 내려놓도록 한다. 이 때 시선은 앞을 보고, 선 상태에서 체중을 지지하는 양다 리를 편안하게 펴도록 한다. 이어 “시작”이라는 신호와 함께 자신이 점프할 수 있는 최대높이로 수직으로 점프하 게 하고, 점프 후 $\mathrm{WBB}$ 에 착지하여 두 발로 선 상태를 유 지하도록 한다. $\mathrm{WBB}$ 로 측정된 데이터는 체중 지지 단계 (weight phase), 비체중부하 단계(unweighting phase), 제 동 단계(braking phase), 추진 단계(propulsion phase), 체 공 단계(flight phase), 착지 단계(landing phase)로 구분 할 수 있다. 분석에는 점프 시간(s), 각 단계에서 최대 힘 (체중\%), 접지 시간(ground contact time, s), 각 단계별 시간을 사용하였다. 분석된 정보는 블루투스로 연결된 컴 퓨터 장치에 기록되었다. 모든 대상자는 측정을 시작하기 전 점프를 충분히 연습하도록 하게 하고, 3 번씩 측정하였 다. 각 평가 동작 사이에는 1 분간 휴식을 취하게 하였다. 낙상에 대비하기 위해 모든 동작에서 평가자가 $1 \mathrm{~m}$ 이내 에 대기하였다. 


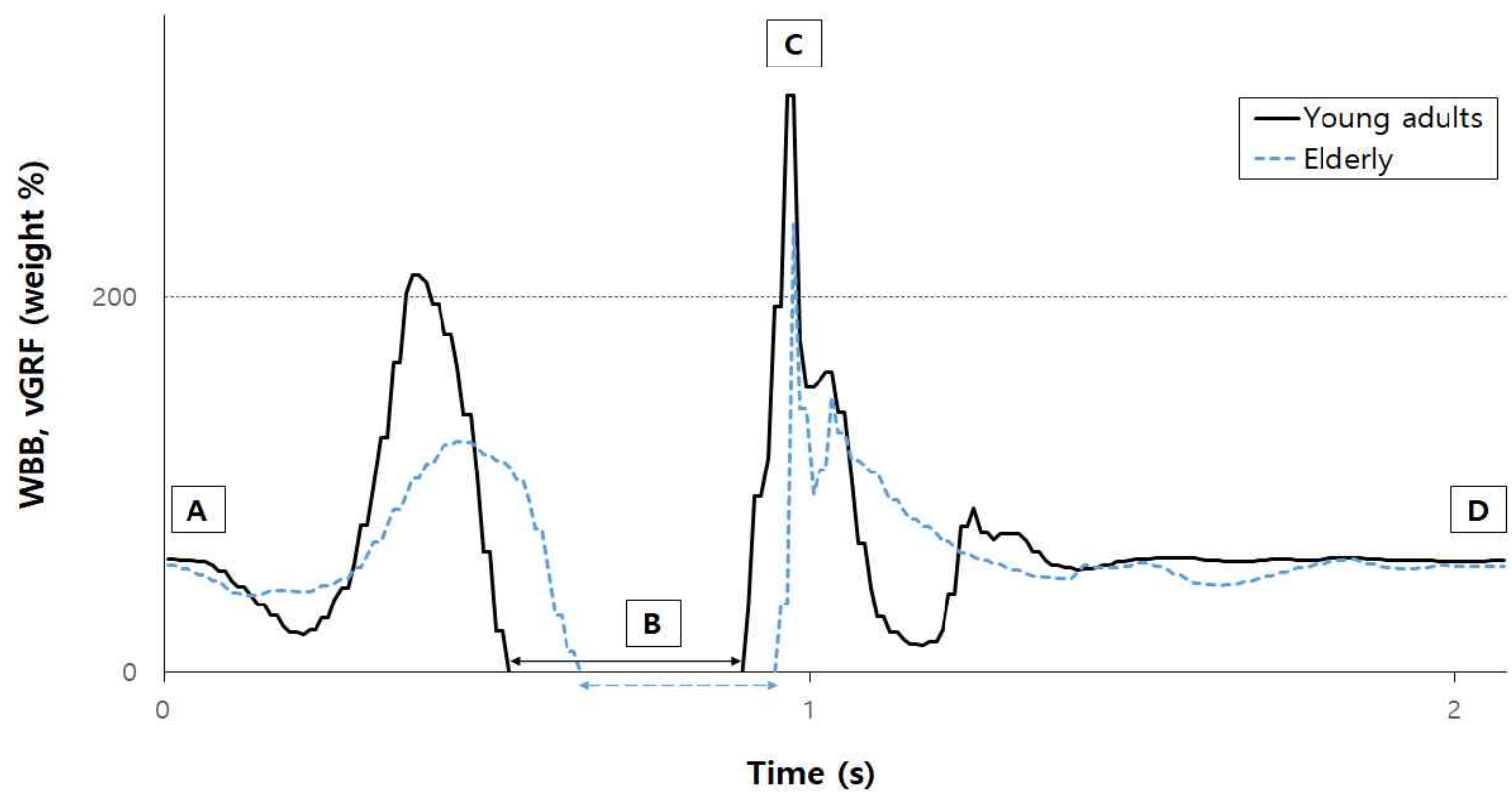

Figure 1. Procedure of vertical jump and each example data of vertical groun reaction force (vGRF) in young adults and elderly using the Wii Balance Board (WBB): (A-D) total jump time, (B) flight phase, (C) peak phase.

\section{자료 분석}

기술통계를 사용하여 각 집단의 평균과 표준편차 $(\mathrm{Mean} \pm \mathrm{SD})$ 를 산출하였다. 두 군 간의 일반적 특성을 비 교하기 위해 카이제곱 검정(Chi-square test) 및 독립표본 T검정(Independent t-test)을 사용하였다. Shapiro-Wilk 정규성 검정 결과에 따라 노인군과 젊은 성인군의 점프의 차이를 확인하기 위해 독립표본 $\mathrm{T}$ 검정(Independent t-test) 또는 맨-휘트니 $U$ 검정(Mann-Whitney $U$ test)을 실시하였다. SPSS(ver. 18.0, IBM Co., USA)으로 본 연 구결과를 분석하였으며, 통계학적 유의성 검증을 위한 유 의수준은 $\alpha=0.05$ 로 하였다.

\section{연구 결과}

\section{일반적 특성}

본 연구에는 젊은 성인 40 명과 노인 33 명이 참여하였 다. 일반적인 특성은 Table 1 과 같으며, 연령을 제외하고 일반적 특성에는 두 군간 유의한 차이가 없었다.

\section{젊은 성인과 노인의 수직 점프 수행력 비교}

수직 점프 수행력을 측정한 결과, 20 대 성인과 65 세 이상 노인 간의 전체 점프 수행시간 $(\mathrm{p}<0.001)$, 수직지면 반발력 최댓값 $(\mathrm{p}=0.005)$, 최솟값 $(\mathrm{p}<0.001)$, 압력 중심점

Table 1. General characteristics of the participants

\begin{tabular}{llll}
\hline & Young adults $(\mathbf{n}=\mathbf{4 0})$ & Elderly $(\mathbf{n}=\mathbf{3 3})$ & p-value \\
\hline Sex (male/female, $\mathrm{n})$ & $20 / 20$ & $16 / 17$ & 0.897 \\
Age (years) & $22.5(2.2)$ & $75.1(5.2)$ & $<0.001$ \\
Weight $(\mathrm{kg})$ & $60.2(10.4)$ & $59.1(7.6)$ & 0.602 \\
Height $(\mathrm{cm})$ & $164.4(5.5)$ & $166.9(6.3)$ & 0.084 \\
Body mass index $\left(\mathrm{kg} / \mathrm{m}^{2}\right)$ & $21.8(2.1)$ & $21.5(2.6)$ & 0.593 \\
\hline
\end{tabular}

Values are presented as mean (SD) 
Table 2. Comparison of Jump performance between elderly and young adults

\begin{tabular}{|c|c|c|c|}
\hline & Young adults $(n=40)$ & Elderly (n=33) & Z-value \\
\hline Time (s) & $1.98(0.44)$ & $2.40(0.41)$ & $-4.203^{* * *}$ \\
\hline Peak (BW\%) & $399.45(80.31)$ & $348.57(66.66)$ & $2.905^{* *}$ \\
\hline $\operatorname{Min}(\mathrm{BW} \%)$ & $-0.29(0.55)$ & $-.03(0.01)$ & $-6.969^{* * *}$ \\
\hline Int_SUM (BW\%) & $197.35(46.65)$ & $241.96(40.98)$ & $-4.293^{* * *}$ \\
\hline COP path length (mm) & $945.24(294.46)$ & $785.83(168.96)$ & $-2.261^{*}$ \\
\hline W difference peak $(\mathrm{kg})$ & $54.55(21.28)$ & $58.38(25.54)$ & -.587 \\
\hline W symmetry ratio (\%) & $1.15(0.23)$ & $1.13(0.21)$ & .537 \\
\hline $\mathrm{X}$ range $(\mathrm{mm})$ & $62.98(66.02)$ & 408.38 (1953.94) & -1.485 \\
\hline$Y$ range $(\mathrm{mm})$ & $56.77(44.22)$ & $227.90(1067.34)$ & -.510 \\
\hline Jump(flight) time (ms) & $40.37(6.36)$ & $21.34(6.60)$ & $12.503^{* * *}$ \\
\hline
\end{tabular}

Values are presented as mean (SD)

BW: body weight, Int_SUM: integral summation, COP: center of pressure.

이동 거리 $(\mathrm{p}=0.024)$, 체공시간 $(\mathrm{p}<0.001)$ 에서 통계학적으 로 유의한 차이가 있었다(Table 2). 노인은 젊은 성인에 비해, 긴 점프 수행시간과 낮은 수직지면반발력, 긴 이동 거리, 짧은 체공시간을 보였다.

\section{고찰}

노인의 하지근력 약화는 노화와 함께 나타나는 신체적 변화이며, 낙상을 일으킬 수 있는 대표적인 요인 중 하나 이다. 노인의 점프 수행력을 기반으로 노화에 따른 하지 근력 약화와 독립적인 일상생활과제 수행 능력을 비교적 간단하게 평가할 수 있다. 본 연구에서는 $\mathrm{WBB}$ 를 사용하 여 보다 정량적이고 간편하게 점프 수행력을 측정하였고, 젊은 성인과 노인을 비교하였다. 그 결과, 노인의 전체 점 프 수행 시간은 젊은 성인보다 더 길었고, 최대 수직지면 반발력은 약 $15 \%$ 더 낮았다. 또한, 노인의 경우 젊은 성 인에 비해 상대적으로 체공 시간이 짧고, 압력 중심점의 이동 거리가 비교적 낮게 나타났다.

본 연구에서는 정량적인 점프 높이를 측정하지 못하였 으나, 기존 연구와 유사한 결과를 보였다. 건강한 성인 10 명과 건강한 노인 10 명을 대상으로 연령에의 영향을 확인 하고자, 반동 점프 수행 동안의 대퇴이두근과 대퇴직근의 근활성도(편심성 및 동심성수축) 및 힘판으로 측정한 수 직지면반발력, 무게중심점 이동 거리, 점프 높이 등을 비 교한 연구[9]의 주요 결과에 따르면, 젊은 성인에 비해 노 인이 실질적으로 더 작은 수직지면반발력과 무게중심점이 동으로 반동 점프를 수행하였다고 보고하였다. 이때 두
집단간의 점프 높이는 약 2 배 이상의 유의한 차이를 보였 다. 본 연구에서 젊은 성인의 체공 시간이 상대적으로 2 배 이상 길었고, 노인의 최대 수직지면반발력과 압력중심 점 이동거리가 젊은 성인보다 각각 약 $-15 \%,-17 \%$ 으로, 통계학적으로 유의한 결과를 보였다. 즉, 점프 동안 연령 증가에 따른 낮은 하지 근활성도 및 수직지면반발력, 압 력중심점의 이동거리를 통해 노인의 하지 근력 약화를 확 인할 수 있다.

본 연구에서는 $\mathrm{WBB}$ 를 통해 수직지면반발력을 확인함 으로써 노인의 하지근력 약화를 간접적으로 알 수 있었다. 힘판을 사용한 기존 연구[12]에서는 남성 노인과 젊은 남 성 성인을 대상으로 수직 점프 동안 각 하지 관절(엉덩 관절, 무릎 관절 및 발목 관절)의 모멘트와 각속도에 따른 하지 관절의 파워를 비교하였다. 그 결과, 남성 노인은 젊 은 남성 성인보다 수직 점프높이는 $64 \%$, 수직지면반발력 은 $26 \%$, 무게중심점의 수직 속도는 $35 \%$ 낮았다. 또한 노 인에게서 건강한 남성 성인보다 모든 하지 관절에서 낮은 파워가 관찰되었다(엉덩 관절: $-60 \%$; 무릎 관절:- $72 \%$; 발 목 관절: $-68 \%$ ). 본 연구 대상자들의 평균 연령은 기존 연구의 남성 노인(74.5 \pm 4.6$)$ 및 젊은 남성 성인(21.8 \pm 2.8$)$ 과 비슷하였으나, 본 연구에서는 남녀 모두가 포함되었기 때문에 두 집단 간의 수직지면반발력 차이가 $15 \%$ 로 비교 적 낮게 나타난 것으로 추측된다.

힘판은 움직임이나 신체적 발달에 대한 평가에 유용한 도구이지만 비용적 부담이 크고, 이동시 무겁다는 제한이 있다. 그러므로 힘판은 임상환경에서는 사용하기 어려움 이 있다[13]. 반면에 $\mathrm{WBB}$ 는 1 축의 센서를 셀 4 개로 사 
용하여 체중값과 압력 중심점과 수직지면반발력을 구할 수 있다[21]. 따라서 힘판의 단점을 보완하며 사용이 간편 하고 이동이 편리한 $\mathrm{WBB}$ 로 점프 수행 시 노인의 수직지 면반발력, 체공 시간, 압력중심점 이동거리 등을 측정함으 로써 노화에 따른 기능적 움직임 능력의 변화를 정량적으 로 확인할 수 있을 것이다.

본 연구의 제한점은 기존에 사용되는 힘판은 3축으로 구성되어 있어 세 방향의 힘을 알 수 있지만 WBB는 1축 으로 구성되어 있어서 수직방향의 지면반발력만 측정이 가능하여 힘판에 비해 세밀한 측정이 불가능하다는 것이 다. 그러나 힘판과 달리, $\mathrm{WBB}$ 는 사용성 측면에서 이동이 편리하고 간편하다는 장점이 있고 힘판과 비교하였을 때 높은 타당도가 입증되었으며 본 연구에서도 $\mathrm{WBB}$ 로 젊은 성인과 노인의 점프 수행력을 변별할 수 있음을 확인하였 다. 이와 같은 타당성을 바탕으로, $\mathrm{WBB}$ 을 통해 노인의 점프 수행력을 평가하고 하지 근력 약화를 확인할 수 있 을 것이다. 추후 연구에서는 $\mathrm{WBB}$ 를 기반으로 노인의 점 프 수행력을 정량적으로 평가하고, 임상적 효과를 확인하 는 결과변수로써 활용한다면 임상 환경에서 정량적 평가 도구에 대한 유용성이 증대할 것이다.

\section{결론}

본 연구는 노인과 젊은 성인을 대상으로 $\mathrm{WBB}$ 를 이용 하여 점프 수행력을 측정하고, 수직지면반발력, 압력중심 점 이동거리, 체공 시간 등을 비교하고자 하였다. 본 연구 결과, 노인은건강한 젊은 성인과 비교하였을 때 긴 점프 시간, 낮은 최대수직지면반발력 및 압력중심점 이동거리, 짧은 체공 시간을 보였다. 변별 타당도가 입증된 $\mathrm{WBB}$ 를 활용한다면 비교적 간편하게 노인의 기능적 움직임을 정 량적으로 평가할 수 있을 것이다.

\section{참고문헌}

1. Tinetti ME, Ginter SF. Identifying mobility dysfunctions in elderly patients: standard neuromuscular examination or direct assessment? JAMA. 1988;259:1190-3.

2. Fiatarone MA, Evans WJ. 11 The Etiology and Reversibility of Muscle Dysfunction in the Aged. J Gerontol. 1993;48:77-83.

3. Siglinsky E, Krueger D, Ward RE, Caserotti P, Strotmeyer ES, Harris TB, et al. Effect of age and sex on jumping mechanography and other measures of muscle mass and function. J Musculoskelet Neuronal Interact. 2015;15:301.
4. VAN ZANDWIJK JP, BOBBERT MF, Munneke M, Pas P. Control of maximal and submaximal vertical jumps. Med Sci Sports Exerc. 2000;32:477.

5. Haguenauer M, Legreneur P, Monteil KM. Vertical jumping reorganization with aging: a kinematic comparison between young and elderly men. J Appl Biomech. 2005;21:236-46.

6. De Vito G, Bernardi M, Forte R, Pulejo C, Macaluso A, Figura F. Determinants of maximal instantaneous muscle power in women aged 50-75 years. Eur J Appl Physiol Occup Physiol. 1998;78:59-64.

7. Holsgaard Larsen A, Caserotti P, Puggaard L, Aagaard P. Reproducibility and relationship of single-joint strength vs multi-joint strength and power in aging individuals. Scand J Med Sci Sports. 2007; 17:43-53.

8. Kim S. Countermovement jump strategy changes with arm swing to modulate vertical force advantage. Korean Journal of Sport Biomechanics. 2017;27:141-7.

9. Liu Y, Peng C-H, Wei S-H, Chi J-C, Tsai F-R, Chen J-Y. Active leg stiffness and energy stored in the muscles during maximal counter movement jump in the aged. J Electromyogr Kinesiol. 2006;16:342-51.

10. Lee S-Y, Kwon M-S. The Effect of Gender Difference in Injury Experience on Biomechanical Variables of Lower Extremity during Two Leg Drop Landing. Journal of the Korean Applied Science and Technology. 2019;36:424-33.

11. Clark RA, Mentiplay BF, Pua Y-H, Bower KJ Reliability and validity of the Wii Balance Board for assessment of standing balance: A systematic review. Gait Posture. 2018;61:40-54.

12. Argaud S, Pairot de Fontenay B, Blache Y, Monteil $\mathrm{K}$. Explosive movement in the older men: analysis and comparative study of vertical jump. Aging Clin Exp Res. 2017;29:985-92.

13. Blosch C, Schäfer R, de Marées $M$, Platen $P$. Comparative analysis of postural control and vertical jump performance between three different measurement devices. PLoS One. 2019;14:e0222502.

14. Mhatre PV, Vilares I, Stibb SM, Albert MV, Pickering L, Marciniak CM, et al. Wii Fit balance board playing improves balance and gait in Parkinson disease. PM R. 2013;5:769-77.

15. Park D-S, Lee D-Y, Choi S-J, Shin W-S. Reliability and validity of the balancia using wii balance board 
for assessment of balance with stroke patients. Journal of the Korea Academia-Industrial cooperation Society. 2013;14:2767-72.

16. Kwok B-C, Clark RA, Pua Y-H. Novel use of the Wii Balance Board to prospectively predict falls in community-dwelling older adults. Clin Biomech. 2015;30:481-4.

17. Yamamoto K, Matsuzawa M. Validity of a jump training apparatus using Wii Balance Board. Gait Posture. 2013;38:132-5.

18. Hardcastle SA, Gregson CL, Rittweger J, Crabtree N, Ward K, Tobias JH. Jump power and force have distinct associations with cortical bone parameters: findings from a population enriched by individuals with high bone mass. J Clin Endocrinol Metab. 2014;99:266-75.

19. Haguenauer M, Legreneur P, Monteil KM. Vertical jumping reorganization with aging: a kinematic comparison between young and elderly men. J Appl Biomech. 2005;21:236-46.

20. Park DS, Lee G. Validity and reliability of balance assessment software using the Nintendo Wii balance board: usability and validation. J Neuroeng Rehabil. 2014;11:1-8.

21. Jeong YJ, Park DS. Validity of ground reaction forces during gait and sit-to-stand using the nintendo wii balance board in healthy subjects. J Korean Soc Phys Med. 2016;11:85-92. 